BMC

Genomics

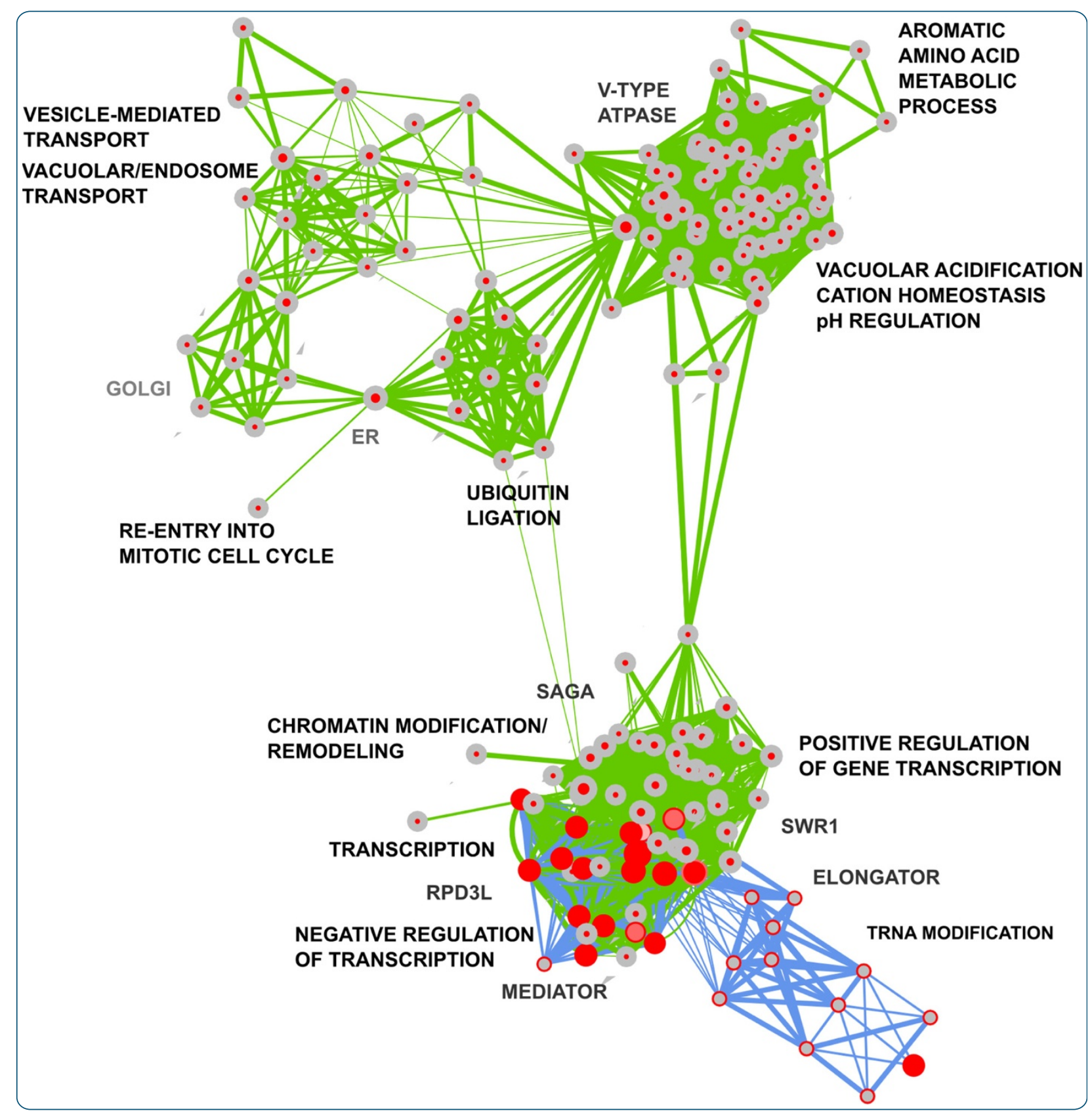

\title{
High throughput screening identifies modulators of histone deacetylase inhibitors
}

Gaupel et al.

() Biomed Central 


\title{
High throughput screening identifies modulators of histone deacetylase inhibitors
}

\author{
Ann-Christin Gaupel ${ }^{1,2}$, Thomas Begley ${ }^{2,3}$ and Martin Tenniswood ${ }^{1,2^{*}}$
}

\begin{abstract}
Background: Previous studies from our laboratory and others have demonstrated that in addition to altering chromatin acetylation and conformation, histone deacetylase inhibitors (HDACi) disrupt the acetylation status of numerous transcription factors and other proteins. A whole genome yeast deletion library screen was used to identify components of the transcriptional apparatus that modulate the sensitivity to the hydroxamic acid-based HDACi, CG-1521.

Results: Screening 4852 haploid Saccharomyces cerevisiae deletion strains for sensitivity to CG-1521 identifies 407 sensitive and 80 resistant strains. Gene ontology (GO) enrichment analysis shows that strains sensitive to CG-1521 are highly enriched in processes regulating chromatin remodeling and transcription as well as other ontologies, including vacuolar acidification and vesicle-mediated transport. CG-1521-resistant strains include those deficient in the regulation of transcription and tRNA modification. Components of the SAGA histone acetyltransferase (HAT) complex are overrepresented in the sensitive strains, including the catalytic subunit, Gcn5. Cell cycle analysis indicates that both the wild-type and gcn5 $\Delta$ strains show a $G_{1}$ delay after CG-1521 treatment, however the gcn5 $\Delta$ strain displays increased sensitivity to CG-1521-induced cell death compared to the wild-type strain. To test whether the enzymatic activity of Gcn5 is necessary in the response to CG-1521, growth assays with a yeast strain expressing a catalytically inactive variant of the Gcn5 protein were performed and the results show that this strain is less sensitive to CG-1521 than the gcn5 $\Delta$ strain.

Conclusion: Genome-wide deletion mutant screening identifies biological processes that affect the sensitivity to the HDAC inhibitor CG-1521, including transcription and chromatin remodeling. This study illuminates the pathways involved in the response to CG-1521 in yeast and provides incentives to understand the mechanisms of HDAC inhibitors in cancer cells. The data presented here demonstrate that components of the SAGA complex are involved in mediating the response to CG-1521. Additional experiments suggest that functions other than the acetyltransferase activity of Gcn5 may be sufficient to attenuate the effects of CG-1521 on cell growth.
\end{abstract}

Keywords: Histone deacetylase inhibitor, CG-1521, Yeast deletion library screen, Histone acetyltransferase, SAGA complex, Gcn5, Chromatin remodeling, Transcription

\section{Background}

Many human cancers display abnormal post-translational modifications of histones, including acetylation [1-4], and histone deacetylases (HDACs) are known to be aberrantly expressed in a variety of cancer cells [5]. It has been suggested that changes in histone modifications and histone

\footnotetext{
* Correspondence: mtenniswood@albany.edu

'Department of Biomedical Sciences, School of Public Health, University at Albany, New York 12222, USA

${ }^{2}$ Cancer Research Center, University at Albany, 1 Discovery Drive, Rensselaer, NY 12144, USA

Full list of author information is available at the end of the article
}

deacetylase expression levels may be useful prognostic indicators of survival and recurrence in a variety of cancers [2-4,6]. Mammalian HDACs can be subdivided into two families: the classical HDAC family and the sirtuins. The classical HDACs are $\mathrm{Zn}^{2+}$ dependent enzymes: class I HDACs (HDACs 1, 2, 3, and 8) share homology to the yeast HDAC Rpd3 and are localized to the nucleus; class II HDACs are related to yeast Hda1 and shuttle between the cytosol and nucleus (HDAC 4, 5, 7, 9) or reside in the cytosol (HDAC 6, 10). HDAC 11 (class IV), homologous to Hos3, resides in the cytosol and nucleus. Over the last 1015 years a variety of natural and synthetic HDAC inhibitors 
have been developed, including hydroxamic acid derivatives, benzamides, short chain fatty acids, cyclic tetrapeptides, and electrophilic ketones. Hydroxamic acid derivatives, including Trichostatin A (TSA), suberoylanilide hydroxamic acid (SAHA) and CG-1521 (7-phenyl-2,4,6hepta-trienoic hydroxamic acid), inhibit the classical family of HDACs by coordinating the catalytic site $\mathrm{Zn}^{2+}$, stabilizing the acetylation of histones and non-histone proteins. This induces a variety of responses including cell cycle arrest, cell death, differentiation and senescence, depending on the cell lines and inhibitors used [7,8]. HDACis are attractive agents because therapeutically active concentrations are minimally toxic to the host and transformed cells are more sensitive to HDACi-induced cell death than normal cells [9-12]. To date, two HDACis, SAHA and Romidepsin, a cyclic tetrapeptide, have been approved by the FDA for the treatment of cutaneous T-cell lymphoma $[13,14]$. Previous studies from our laboratory and others have demonstrated that hydroxamic acid-based HDACis have profound impacts on the biology of prostate and breast cancer cell lines, inducing growth arrest and apoptosis [15-19].

The aim of the research reported here was to identify transcription factors that may be useful for novel therapeutic approaches in combination with HDAC inhibitors for hard-to-treat-cancers. We have taken a systems biology approach, screening a Saccharomyces cerevisiae haploid single gene deletion library, to identify gene products that modulate the response to HDAC inhibition. $S$. cerevisiae is a valuable model organism for which there is a wide array of information available (including transcriptional profiling, interaction studies and synthetic genetic analysis) to use in analyzing new high throughput data sets [20-23]. Furthermore, histones and histone modifying enzymes show a high degree of sequence and functional conservation among eukaryotes [24-27].

\section{Results}

\section{CG-1521-sensitive and-resistant strains are enriched for} genes involved in chromatin remodeling and transcription Genomic phenotyping was performed to detect CG-1521sensitive and -resistant strains. Gene deletion strains were spotted on agar plates containing low $(55 \mu \mathrm{M})$, medium $(67.5 \mu \mathrm{M})$ or high $(72.5 \mu \mathrm{M})$ concentrations of CG-1521. Strain growth was imaged and sensitive and resistant strains were visually identified. Examples of strains with different grades of sensitivity and resistance are shown in Figure 1. 407 sensitive and 80 resistant gene deletion mutants were identified (Additional file 1). S. cerevisiae is more resistant to the hydroxamic acid based HDACi TSA and SAHA. Sensitive strains can only be identified with concentrations starting at $150 \mu \mathrm{M}$ TSA, while SAHA does not induce changes in growth up to concentrations of $1.75 \mathrm{mM}$

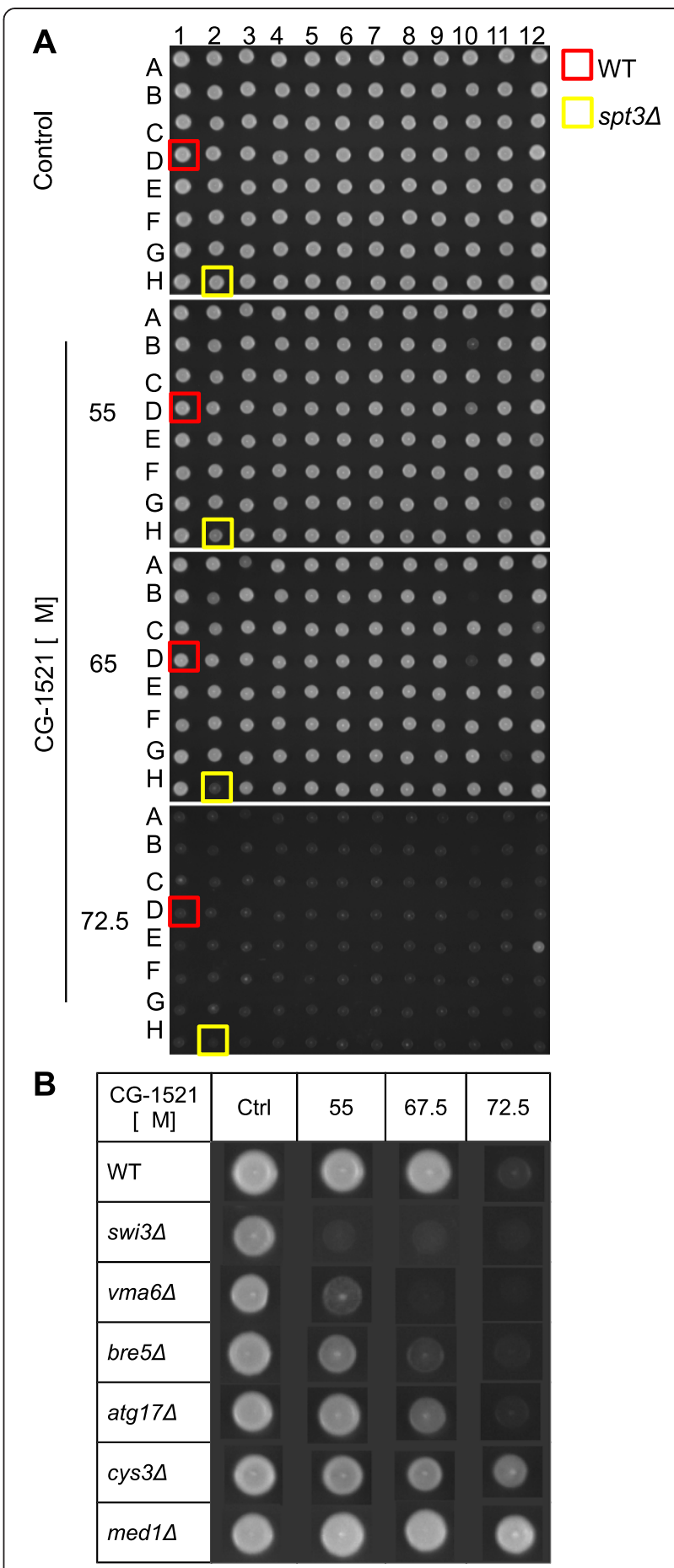

Figure 1 Genomic phenotyping with CG-1521. Panel A. Representative YPD agar plates. 4852 yeast gene deletion strains, arrayed on 96 well plates, were tested for sensitivity and resistance to CG-1521. Strains, grown to stationary phase, were spotted on agar plates containing the indicated concentrations of CG-1521. Plates were imaged after $60 \mathrm{~h}$. The BY4741 wild-type strain (red) and the CG-1521-sensitive strain spt $3 \triangle$ (yellow) were spotted on each plate as controls. Panel $\mathbf{B}$. Examples of strains displaying sensitivity or resistance to CG-1521. Images of wild-type, swi $\Delta$, , vma $6 \Delta$, bre $5 \Delta$, atg $17 \Delta$, cys $3 \Delta$ and med $1 \Delta$ were compiled to show varying degrees of sensitivity or resistance to CG-1521. 
SAHA (data not shown). Due to these limitations, it is not feasible to identify sensitive and resistant strains in response to TSA and SAHA.

Gene ontology (GO) analysis using DAVID was used to determine which functional classes are enriched in proteins corresponding to the list of sensitive and resistant gene deletion strains [28]. Gene deletion mutants that are sensitive to CG-1521 are highly enriched in processes regulating chromatin organization and transcription (Table 1). Proteins corresponding to the gene deletion strains resistant to CG-1521 are enriched for those involved in tRNA modification (GO:0006400) and regulation of transcription, DNA-dependent (GO:0006355) and its child, negative regulation of transcription (GO:0045 892). The other child, positive regulation of transcription (GO:0045893), was not significantly enriched (Table 2). Deletion of complexes associated with chromatin conformation, the HAT and HDAC complexes that modulate histone acetylation, the compass complex, which modulates histone methylation and the Swi/Snf, Swr1 and Ino80 complexes that are central to changes in chromatin conformation, all confer sensitivity to CG-1521 (Figure 2). Proteins of several other biological processes associated with transcriptional regulation, modulate the response to CG-1521, including elongation factors (THO complex, Paf1 complex, transcription elongation factor complex) and CTD kinases, as well as other modulators of transcription. Additionally, cellular machineries of translation and mRNA processing, including poly(A)-modification, mRNA degradation and splicing affect the sensitivity to CG-1521. Gene products of several other biological processes, including vacuolar acidification, vacuolar protein sorting, vesicle-mediated transport, DNA repair and cell cycle regulation (Figure 2,
Additional file 2) predominantly decrease the sensitivity to CG-1521. Deletion mutants, lacking genes important for bud site selection, recovery from arrest in response to pheromone, $G_{1} / S$ and $G_{2} / M$ progression and cytokinesis are sensitive to CG-1521. Components of the Mediator and Elongator complexes are enriched in the resistant strains. Since the Elongator complex has roles in transcription elongation and wobble nucleoside modification in tRNA, it is not clear whether one or both processes are important in the response to CG-1521 (Figure 2).

To confirm the sensitivity of the strains a secondary screen was performed in liquid culture as detailed in Methods (Additional file 3). Sixty five of seventy two tested sensitive strains were validated. These encompass gene deletion mutants that lack genes involved in transcription (CTK1-3, THO and Paf1 complex, transcription factors) and chromatin remodeling, including components of the Rpd3L (Dep1, Sin3, Pho23, Ume1, Rxt2, Sap30), Swr1 (Yaf9, Htz1, Swc5, Swc3, Arp6, Swr1, Swc2) and the Gcn5 HAT complex (Gcn5, Ada2, Ngg1, Sgf73, Spt3, Spt7, Spt8, Hfi1).

\section{Loss of Gcn5 HAT complexes confers sensitivity to CG-1521}

Deletion mutants associated with Gen 5 HAT complexes are overrepresented $(\mathrm{p}=6.2 \mathrm{E}-4)$ in the CG-1521-sensitive strains (SAGA (Spt-Ada-Gcn5-acetyltransferase) complex) (Figure 3). Gcn5 is a component of three HAT complexes in S. cerevisiae, the ADA, SAGA and SLIK (SAGA-like) complexes. Of the sixteen components that have corresponding deletion strains in the library, ten are sensitive (Gcn5, Ada2, Ngg1, Sgf29, Sgf73, Spt3, Spt7, Spt8, Spt20, Hfil, red) and six are not sensitive (Ubp8, Sgf11, Chd1, Rtg2, Ahc1, Ahc2, blue). Deletion of Spt20, Spt7, Gcn5 and

Table 1 Gene ontology analysis of CG-1521-sensitive strains using DAVID bioinformatics

\begin{tabular}{|c|c|c|c|c|}
\hline \multicolumn{5}{|l|}{ Gene ontology analysis: sensitive strains } \\
\hline Category (GO-FAT) & & p-value & Corrected p-value & Represented strains \\
\hline Chromosome Organization & GO:0051276 & $4.5 \mathrm{E}-5$ & $1.5 \mathrm{E}-3$ & 49 \\
\hline Chromatin Organization & GO:0006325 & $1.2 \mathrm{E}-8$ & $7.1 \mathrm{E}-6$ & 41 \\
\hline Chromatin Modification & GO:0016568 & $1.4 \mathrm{E}-7$ & 4.3E-5 & 35 \\
\hline Histone Modification & GO:0016570 & $6.5 \mathrm{E}-7$ & $1.3 \mathrm{E}-4$ & 23 \\
\hline Histone Exchange & GO:0043486 & 3.1E-4 & $7.0 \mathrm{E}-3$ & 6 \\
\hline Transcription & GO:0006350 & $1.7 \mathrm{E}-6$ & $2.1 \mathrm{E}-4$ & 69 \\
\hline Regulation of Transcription & GO:0045449 & $7.0 \mathrm{E}-8$ & $2.8 \mathrm{E}-5$ & 82 \\
\hline Positive Regulation of Transcription & GO:0045941 & $6.1 \mathrm{E}-6$ & $3.8 \mathrm{E}-4$ & 30 \\
\hline Negative Regulation of Transcription & GO:0016481 & $1.1 \mathrm{E}-5$ & $5.6 \mathrm{E}-4$ & 32 \\
\hline Regulation of Transcription from RNA Pol II Promoter & GO:0006357 & $5.2 \mathrm{E}-3$ & $6.9 \mathrm{E}-2$ & 31 \\
\hline SAGA Complex & GO:0000124 & $6.9 \mathrm{E}-6$ & $6.2 \mathrm{E}-4$ & 10 \\
\hline Swr1 Complex & GO:0000812 & $1.8 \mathrm{E}-3$ & $2.6 \mathrm{E}-2$ & 6 \\
\hline Rpd3L Complex & GO:0033698 & $1.8 \mathrm{E}-3$ & $2.6 \mathrm{E}-2$ & 6 \\
\hline
\end{tabular}

Four hundred and seven sensitive strains were identified. Reported $\mathrm{p}$ values have been corrected using the methods described by Benjamini and Hochberg. The GO FAT database, developed as part of DAVID, removes very broad GO terms and comprises more specific terms [28,29]. 
Table 2 Gene ontology analysis of CG-1521-resistant strains using DAVID bioinformatics

\begin{tabular}{|c|c|c|c|c|}
\hline \multicolumn{5}{|l|}{ Gene ontology analysis: resistant strains } \\
\hline Category (GO-FAT) & & p-value & Corrected p-value & Represented strains \\
\hline tRNA Modification & GO:0006400 & $2.2 \mathrm{E}-4$ & $1.1 \mathrm{E}-2$ & 7 \\
\hline tRNA Wobble Uridine Modification & GO:0002098 & $6.9 \mathrm{E}-7$ & $3.2 \mathrm{E}-4$ & 7 \\
\hline Transcription & GO:0006350 & 1.1E-2 & $0.19+$ & 15 \\
\hline Regulation of Transcription, DNA-dependent & GO:0006355 & $2.9 \mathrm{E}-6$ & $6.6 \mathrm{E}-4$ & 20 \\
\hline Negative Regulation of Transcription & GO:0045892 & $6.5 \mathrm{E}-5$ & $5.9 \mathrm{E}-3$ & 11 \\
\hline Regulation of Transcription from RNA Pol II Promoter & GO:0006357 & $2.4 \mathrm{E}-5$ & 2.7E-3 & 14 \\
\hline Srb Mediator Complex & GO:0016592 & $1.1 \mathrm{E}-5$ & $1.7 \mathrm{E}-3$ & 6 \\
\hline
\end{tabular}

Eighty resistant strains were identified in the yeast gene deletion library screen. Reported $\mathrm{p}$ values have been corrected using the methods described by Benjamini and Hochberg. The GO FAT database, developed as part of DAVID, removes very broad GO terms and comprises more specific terms [28,29]. tCorrected p-values not significant.

Ada2 results in high sensitivity to CG-1521 (scores 10-12).

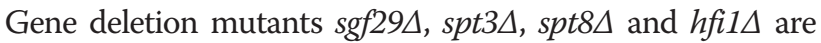
moderately sensitive (scores 6-7) and ngg1 $1 \Delta$ and sgf73 $\Delta$ display low sensitivity (score 5 and 4). Sensitivity scores from the screen and the human homologs of the Gcn5 HAT complex components can be found in Additional file 4 .
The ADA, SAGA and SLIK complexes share the HAT core module, consisting of the catalytically active histone acetyltransferase Gcn5, Ada2, Ada3/Ngg1 and Sgf29. Deletion of any of these genes confers sensitivity to CG-1521 treatment. In contrast, deletion of ADA or SLIK specific components does not result in sensitivity to CG-1521,

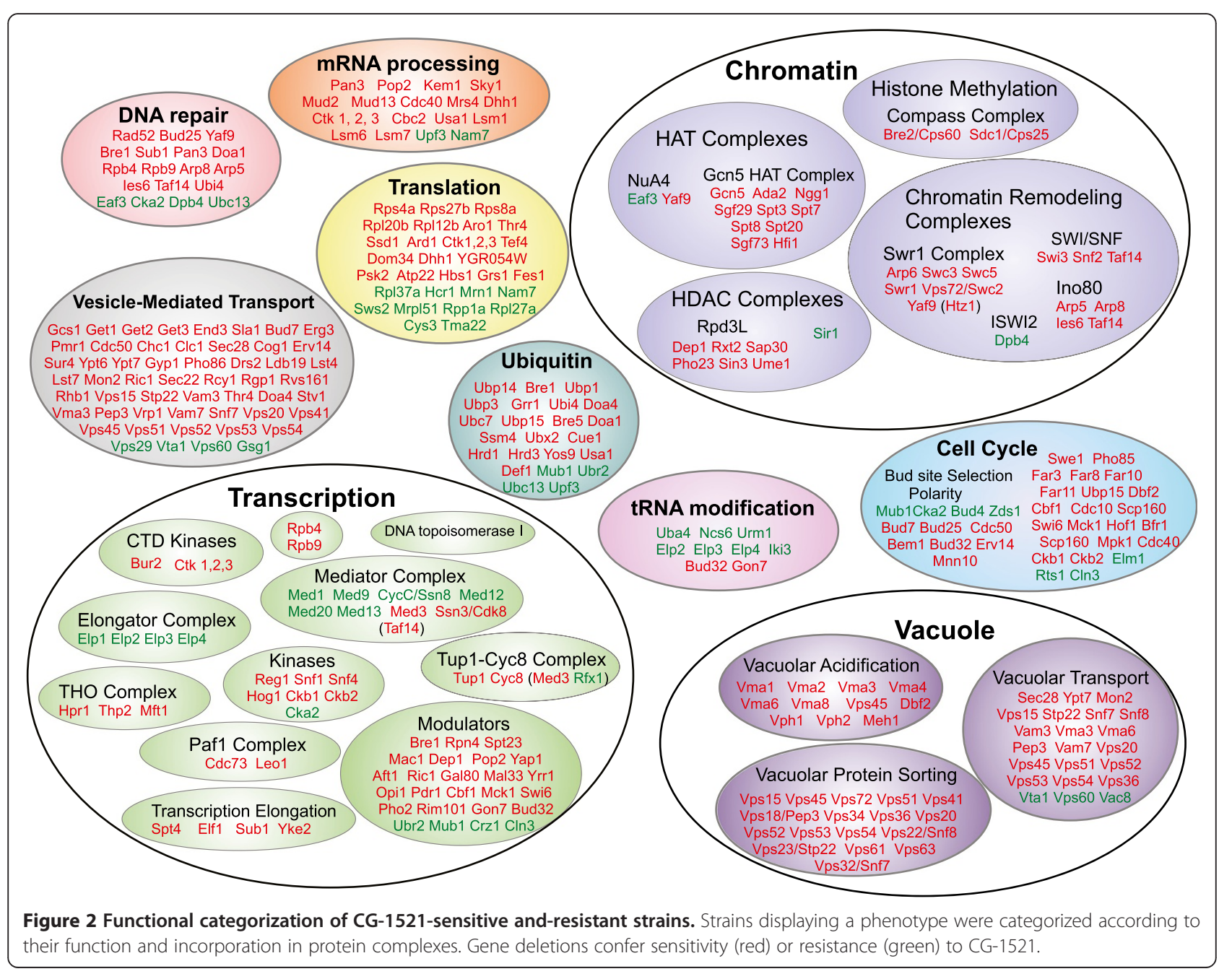




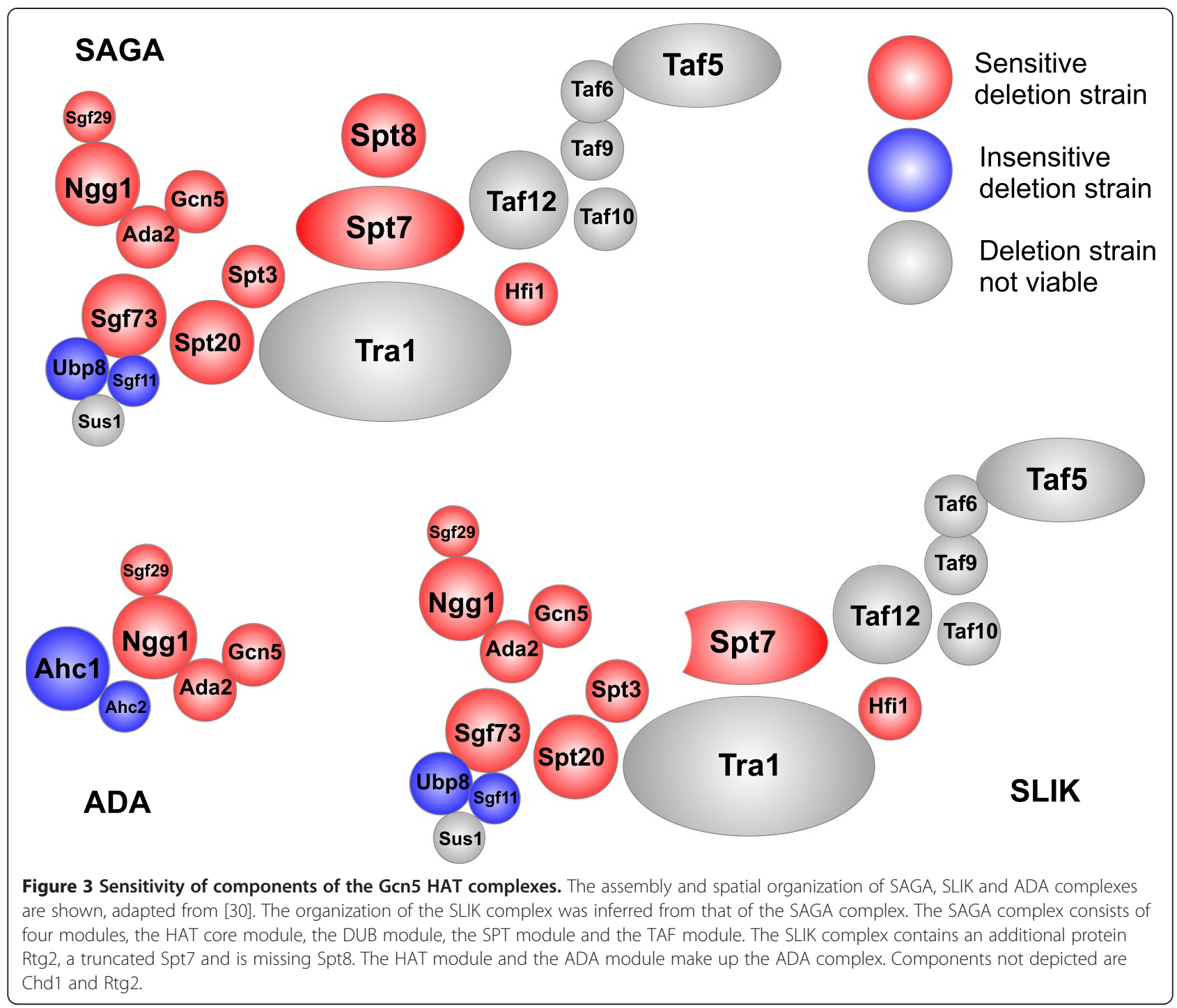

suggesting that the SAGA complex is required to reduce inhibitory effects of CG-1521 on cell growth. Deletion of the deubiquitination (DUB) module components, Ubp8 and Sgf11, does not sensitize cells to CG-1521, indicating that other functions of the SAGA complex are critical for the response to CG-1521.

The sensitivity of strains lacking components of these HAT complexes has been validated on agar plates using several starting cell densities as well as three different concentrations of CG-1521 (Figure 4). The most sensitive strains are $h f i 1 \Delta$ and spt20 , displaying sensitivity at $25 \mu \mathrm{M}$ CG-1521. Most deletion mutants demonstrate the same sensitivity to CG-1521 as in the initial screen, however, the sensitivity of the $h$ fil $\Delta$ mutant is enhanced compared to the screen and yeast deletion mutants $n g g 1 \Delta$ and spt3A show slightly increased sensitivity.

To confirm that the sensitivity of the gcn $5 \Delta$ strain is due to the loss of GCN5, the sensitivity of the GCN5 complemented strain (BY4741 gcn5 $\Delta$, transformed with p416-TEF7-GCN5) was compared to the BY4741 wildtype and the gcn5 $\triangle$ strain. Complementation with GCN5 results in a similar level of resistance as the wild-type (Figure 5), highlighting an important role for Gcn5 in modulating the biological response to CG-1521. To assess the importance of the acetyltransferase function of Gcn5 in the attenuation of CG-1521 activity, the sensitivity of the catalytic site mutant Gen 5 E173Q, which has minimal residual catalytic activity [31], was measured in liquid culture. As shown in Table 3, compared to the wild-type, the $g c n 5 \Delta$ mutant is sensitive at 25 and $50 \mu \mathrm{M}$ CG-1521. The E173Q catalytic site mutant is sensitive to CG-1521, but to a lesser extent than the $g c n 5 \Delta$ mutant $(\mathrm{p}<0.05)$, suggesting that functions other than the acetyltransferase activity of Gcn 5 play a role in the response to CG-1521 and may be sufficient to maintain cell growth. 

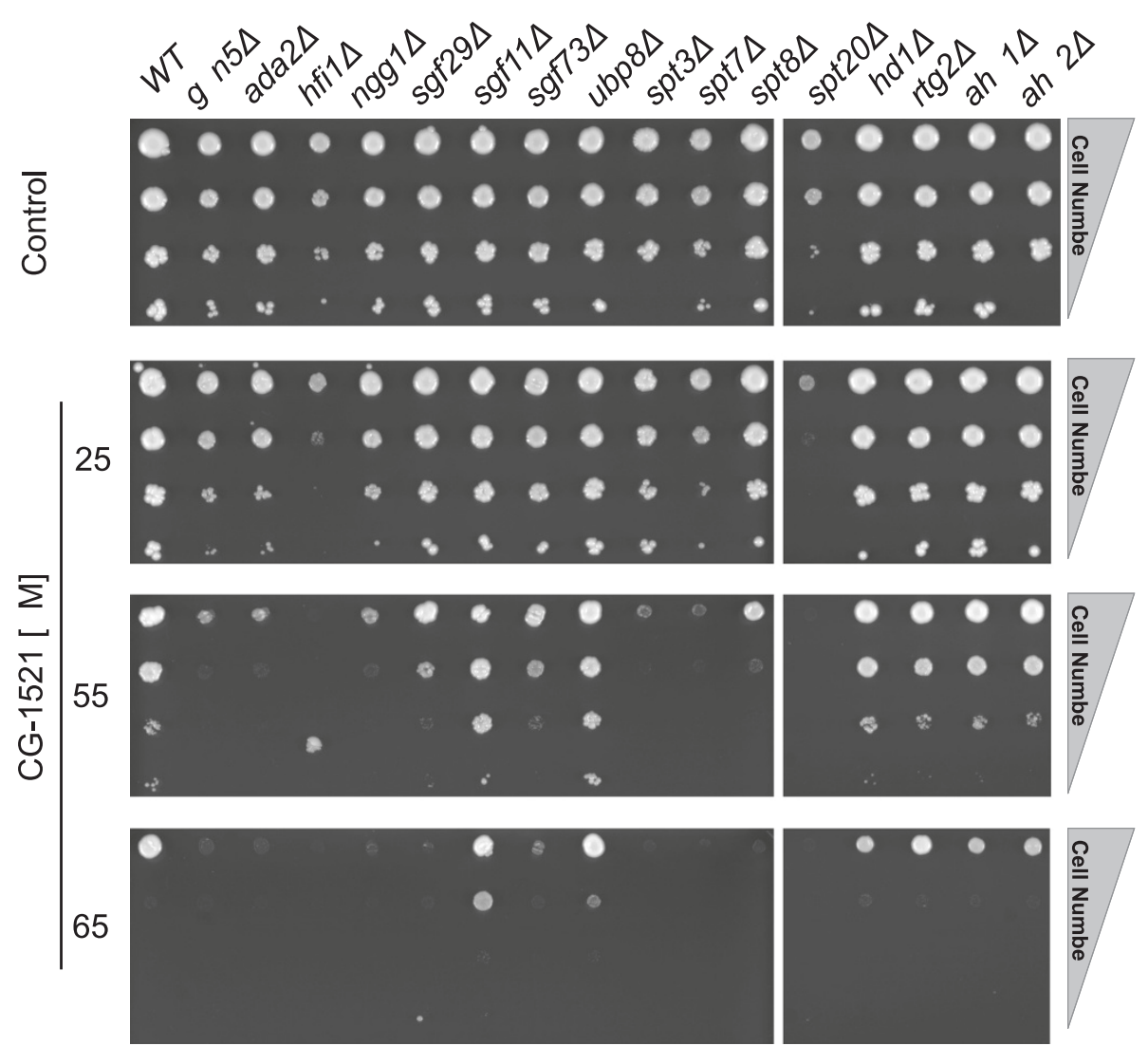

Figure 4 Validation of Gcn5 HAT complex components sensitivity to CG-1521. One $\mu \mathrm{L}$ cell suspension was spotted on CG-1521 containing agar plates, containing 25, 55 or $65 \mu \mathrm{M}$ CG-1521, incubated for $60 \mathrm{~h}$ and imaged as described in Methods. The experiment was repeated three times. Gene deletion mutants spt84 and spt204 are not adjacent, however all deletion mutants are on the same agar plate. Strains lacking Gcn5, Ada2, Hfi1, Ngg1, Sgf29, Sgf73, Spt3, Spt7, Spt8 and Spt20 are sensitive to CG-1521.

CG-1521 treatment results in $\mathrm{G}_{0} / \mathrm{G}_{1}$ delay and deletion of GCN5 increases susceptibility to cell death

Based on the reported involvement of Gcn5 in cell cycle [32,33], the effects of CG-1521 on cell cycle progression in wild-type and $g c n 5 \Delta$ cells were compared. The growth inhibitory effect of CG-1521 is more pronounced in the $g c n 5 \Delta$ strain than in the wild-type strain as determined on agar plates and in liquid culture. Cell cycle analysis shows that CG-1521 induces $\mathrm{G}_{0} / \mathrm{G}_{1}$ arrest in both strains (Figure 6). Treatment with $50 \mu \mathrm{M}$ CG-1521 leads to a significant increase in the $G_{0} / G_{1}$ population after $1 \mathrm{~h}$ and $2 \mathrm{~h}$ for the wild-type and the gcn5 $\Delta$ strain respectively, indicating that the growth arrest is delayed in the gcn5 $\Delta$ strain compared to the wild-type strain. At $4 \mathrm{~h}$, the $\mathrm{G}_{0} / \mathrm{G}_{1}$ population increases by 1.8 fold after treatment with CG-1521 in both the wild-type and the gcn $5 \Delta$ strain. The induction of $\mathrm{G}_{0} / \mathrm{G}_{1}$ delay by CG-1521 was confirmed by budding index analysis (Table 4). Treatment with $50 \mu \mathrm{M}$ CG-1521 reduces the budding index by approximately $50 \%$ in both wild-type and gcn5 $\Delta$ strains by $2 \mathrm{~h}$ to $4 \mathrm{~h}$. As a positive control for $\mathrm{G}_{1}$ arrest, both strains were treated with $5 \mu \mathrm{g} / \mathrm{mL} \alpha$-factor, which reduces the budding index to approximately 0.1 after $2 \mathrm{~h}$ in both strains.

CG-1521 significantly induces cell death in both gcn5 and wild-type strain, as measured by propidium idodide uptake using flow cytometry. As shown in Figure 7, the gcn5 strain displays increased susceptibility to CG1521-induced cell death compared to the wild-type strain. The difference is evident as early as $1 \mathrm{~h}$ after treatment with CG-1521 ( $\mathrm{p}<0.05)$. The gcn5 $\Delta$ strain shows increased cell death after $1 \mathrm{~h}$, whereas cell death in the wild-type strain increases significantly after $2 \mathrm{~h}$. By $4 \mathrm{~h}$ propidium iodide uptake is detectable in $6.7 \%$ of the wild-type population, compared to $16.6 \%$ of the gcn $5 \Delta$ population.

\section{Discussion}

The global decrease in histone modification, particularly methylation and acetylation correlates with an aggressive phenotype and poor prognosis in a number of cancers including prostate, lung and kidney cancer [2,3]. The ability of HDACis to induce death in a variety of cell lines is well documented, however the mechanisms by 


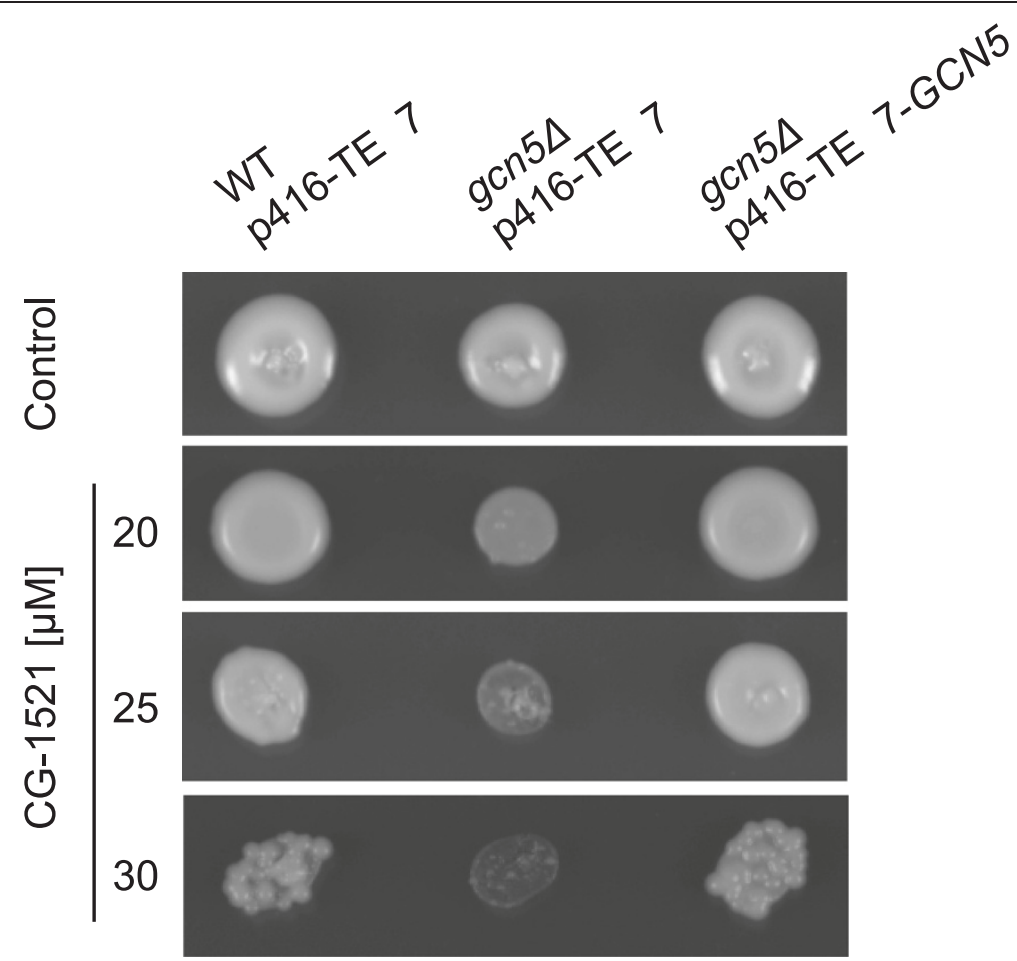

Figure 5 Complementation with GCN5 rescues from the effects of CG-1521. BY4741 p416-TEF7, BY4741 gcn5 $\triangle$ p416-TEF7 and BY4741 gcn5 p416-TEF7-GCN5 were spotted on SD-URA agar plates containing 20, 25 and $30 \mu \mathrm{M} \mathrm{CG-1521}$ and incubated for $60 \mathrm{~h}$ as described in Methods.

The experiment was performed in triplicate.

which they exert their effects are incompletely understood [34-36]. Since many biological processes are regulated by acetylation [37], we have used a yeast deletion library screen to gain insights into the cell growth inhibition mechanisms of HDAC inhibitors and to identify novel targets for combination treatments with the HDACi CG-1521. Choosing S. cerevisiae as a model organism decreases the complexity, however the high degree of functional homology among eukaryotes enables

Table 3 Effect of CG-1521 on cell growth of wild-type, gcn5 $\Delta$ and $g$ cn 5 catalytic site mutant strains

\begin{tabular}{llll}
\hline \multicolumn{2}{l}{ OD600 fraction of control } & & \\
\hline CG-1521 $[\mu \mathrm{M}]$ & & 25 & 50 \\
BY4741 & WT & & $0.87 \pm 0.04$ \\
BY4741 & gcn54 & & $0.26 \pm 0.18$ \\
DY2396 & WT & $0.88 \pm 0.05$ & $0.54 \pm 0.06$ \\
DY5925 & gcn54 & $0.48 \pm 0.06$ & $0.15 \pm 0.04$ \\
DY6603 & gcn5(E173Q) & $0.71 \pm 0.09$ & $0.21 \pm 0.07$
\end{tabular} *

Early-log phase BY4741 cells were treated with 25, 50 MM CG-1521 or vehicle control (DMSO) for $20 \mathrm{~h}$. Cell growth was measured and the ratio of OD600 (CG-1521 cells/DMSO treated cells) was determined as described in Methods. The experiment was performed in 6 independent replicates (BY4741) or 7 independent replicates for DY2396/DY5925/DY6603 strains. The data represent the mean $\pm \mathrm{SD}$. $\left(^{\dagger}, *\right.$ Comparisons are considered significant if $\mathrm{p}<0.05$; within each treatment group all combinations are significantly different from each other). the identification of pathways that are important in the response to CG-1521. For example, mitotic analysis after exposure to TSA shows disruption of centromeric heterochromatin, mitotic delay and chromosome segregation defects in both fission yeast [38,39] and mammalian cells [40,41]. Eukaryotic cells have varied responses to HDACis, which in mammalian cells is partially dictated by the p53 status of the cell lines. For example, treatment of LNCaP prostate cancer cells, which express wild-type p53, with CG-1521 induces $\mathrm{G}_{2} / \mathrm{M}$ arrest and apoptosis [15]. In contrast, TSA induces $G_{1} / S$ arrest [18]. These differences in biological response have been attributed to differences in the site specific acetylation of p53, stabilized by these two drugs [19]. However, MCF-7 breast cancer cells, which express wild-type p53 and SUM190PT, which express mutant p53 both arrest in $G_{0} / G_{1}$ after treatment with either CG-1521 or TSA, suggesting that the complement of HDACs present in the cells also plays a significant role in dictating the biological outcome of treatment.

Despite the roles of histone acetyltransferases and histone deacetylases in DNA replication and DNA repair, cytoskeleton dynamics and cell cycle, these functional classes are not significantly enriched in our screen [37]. However CG-1521-sensitive strains are significantly enriched in vesicle-mediated transport, endocytosis and 


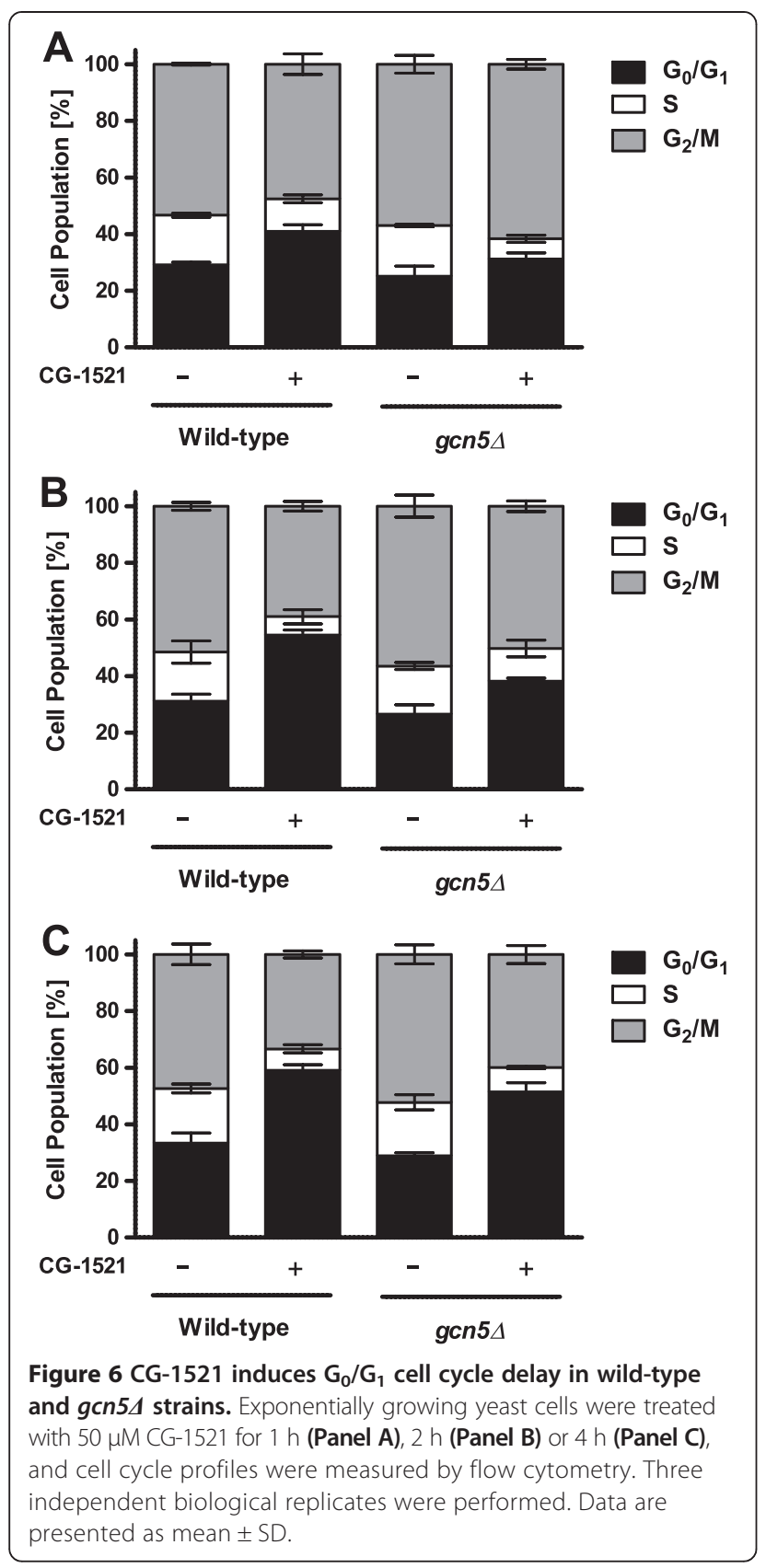

ubiquitin ligation (Additional file 2), which have been shown to be regulated by acetylation [37].

Previous studies have identified 63 gene deletion mutants that result in reduced H3K18 acetylation levels in $S$. cerevisiae [42]. These include genes associated with vacuolar-protein sorting, V-ATPase and SAGA complexes. Twenty-four of these 63 strains were identified as sensitive to CG-1521 in the present study. Deletion of additional genes associated with vacuolar acidification, the vacuolar proton-transporting V-type ATPase complex and vacuolar transport also renders yeast cells
Table 4 CG-1521 induces a budding index decrease in wild-type and $g c n 5 \Delta$ strains

\begin{tabular}{|c|c|c|c|}
\hline \multicolumn{4}{|c|}{ Budding index analysis } \\
\hline \multirow[t]{2}{*}{ Strain } & \multirow[t]{2}{*}{ Treatment } & \multicolumn{2}{|c|}{ Budding index } \\
\hline & & $2 \mathrm{~h}$ & $4 \mathrm{~h}$ \\
\hline \multirow[t]{3}{*}{ WT } & Control & $0.50 \pm 0.05$ & $0.48 \pm 0.03$ \\
\hline & $50 \mu \mathrm{M}$ CG-1521 & $0.30 \pm 0.03^{*}$ & $0.16 \pm 0.07^{*}$ \\
\hline & $5 \mu \mathrm{g} / \mathrm{mL}$ a-factor & $0.10 \pm 0.05^{*}$ & $0.25 \pm 0.03^{*}$ \\
\hline \multirow[t]{3}{*}{ gcn54 } & Control & $0.44 \pm 0.04$ & $0.44 \pm 0.07$ \\
\hline & $50 \mu \mathrm{M}$ CG-1521 & $0.25 \pm 0.04^{*}$ & $0.23 \pm 0.07^{*}$ \\
\hline & $5 \mu \mathrm{g} / \mathrm{mL}$ a-factor & $0.12 \pm 0.04^{*}$ & $0.33 \pm 0.07$ \\
\hline
\end{tabular}

The budding index was determined as described in Methods. The data represent the mean \pm SD of five independent biological replicates

( ${ }^{*}$ Comparisons are considered significant if $p<0.05$ compared to control).

sensitive to CG-1521. Potentially, these CG-1521sensitive strains are characterized by decreased histone acetylation and Gcn5 HAT activity as well. This suggests that disrupting the dynamics of acetylation and deacetylation renders cells sensitive to CG-1521.

Strains lacking components of the Gcn5 HAT complexes are very sensitive to CG-1521. Deletion of any of the four components of the histone acetyltransferase module (Sgf29, Ngg1, Ada2 or Gcn5) renders S. cerevisiae sensitive to CG1521 and deletion of components of the SPT module (Spt3, Spt7, Spt8, Spt20, Hfi1) also results in increased sensitivity to CG-1521. As the Taf module components (Taf5, Taf6, Taf9, Taf10 and Taf12) and Tra1 are essential for cell survival, it is not possible to determine whether deletion of these proteins also confers sensitivity to CG-1521.

The absence of several deletion strains from the list of sensitive strains is also notable. Loss of the Ubp8 and Sgf11 components of the deubiquitination module does not sensitize the cells to CG-1521. Ubp8 and Sgf11 are part of a discrete functional module within the SAGA complex as suggested by genetic interaction and microarray analysis [43] and Ubp8 is dispensable at promoters of several SAGA-dependent genes [44]. These results suggest that the effects of CG-1521 are not modulated by the deuibiquitination activities associated with the SAGA complex. CG-1521 exhibits an increased growth inhibitory effect on the $s g f 73 \Delta$ strain compared to the wild-type. Sgf73 tethers the DUB module to the SAGA complex [45] and recruits the complex to its substrate to stimulate the formation of the pre-initiation complex [46]. It is probable that the sensitivity of the sgf73 $\Delta$ strain to CG-1521 is due to its latter role in the formation of the pre-initiation complex.

Deletion of the SLIK specific component Rtg2, which, in association with Rtg1, Rtg3, Mks1, Lst8 and Tor1 is also responsible for mediating signaling between the mitochondrion and nucleus [47-52] does not alter the response to CG-1521. Since Rtg2 is required for SLIK 


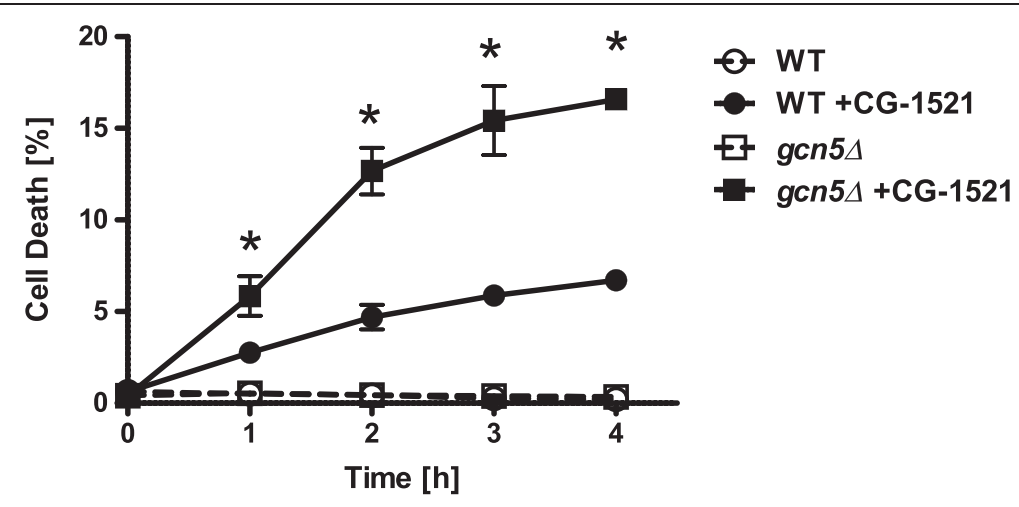

Figure 7 Comparison of CG-1521-induced cell death in wild-type and gcn54 strains. Exponentially growing yeast cells were treated with $50 \mu \mathrm{M}$ CG-1521. Cell death was assessed by propidium iodide uptake and propidium iodide positive cells were quantitated by flow cytometry. The experiment was repeated three times. Data are presented as mean $\pm S D\left({ }^{*} p<0.05\right)$.

integrity [53], this suggests that the SLIK complex is not necessary for eliciting a response to CG-1521. In addition, deletion of ADA (Ahc1, Ahc2) specific components does not sensitize cells to CG-1521, indicating that it is the SAGA complex, rather than ADA or SLIK complexes, that reduces the growth-inhibitory effects of CG-1521.

The SAGA complex may also act as physical adapter independent of Gcn 5 and recruit TBP through Spt3 and Spt8. For example, it has been shown that $\mathrm{H} 3$ acetylation and HAT activity at the Gal1 promoter are not necessary for the formation of the pre-initiation complex, however pre-initiation complex assembly on the Pho84 promoter requires Gcn5 activity $[44,46]$. Gene expression analysis also demonstrates that expression of distinct sets of genes is dependent on individual SAGA subunits [54]. Thus it appears that the requirement for Gon 5 activity is gene specific, suggesting that genes that require Gcn5 for their transcription are required to ameliorate the effect of CG-1521.

The data suggest that other functions of Gcn5, besides the catalytic activity, influence the response to CG-1521 since catalytic site mutation does not confer the same extent of sensitivity as GCN5 deletion. The bromodomain of Gen5 may recruit the HAT complex to acetylated histones. Studies in mice also indicate that there is a difference between gene deletion and catalytic site mutation. Deletion of the murine Gen5 homolog is embryonic lethal, as the mice show increased apoptosis in mesodermal lineages. However, mouse embryos expressing a catalytically inactive protein survive significantly longer and die as a result of exencephaly [55]. These and results presented here indicate that Gcn 5 has important functions that are independent of its HAT activity.

The mechanism by which CG-1521 elicits its growthinhibitory action is probably multifactorial. As an HDAC inhibitor it differentially regulates gene expression and influences activity, stability, and assembly of protein complexes through protein acetylation. Similarly, it is likely that the SAGA complex components, including Gcn5, regulate multiple pathways in response to CG1521, which protect the cell. Potential targets of CG1521 that may account for the sensitivity of the gcn5 $\Delta$ strain were analyzed through identification of negative genetic interactions with GCN5 deletion that display insensitivity to CG-1521. Gene ontology analysis of deletion strains that are insensitive to CG-1521 and are synthetic lethal with GCN5 deletion shows an enrichment in processes like chromatin modification, transcriptional regulation, histone acetylation, DNA repair and response to stress. Notably, deletion of components of the Rpd3 histone deacetylase complexes (Rpd3, Ash1, Pho23, Rxt2, Sap30, Sds3, Sin3 and Eaf3) results in negative genetic interactions with GCN5 deletion, suggesting that the inhibition of Rpd3 by CG-1521 may contribute to the sensitivity of the $\operatorname{gcn} 5 \Delta$ strain to CG-1521. The CG-1521-sensitive

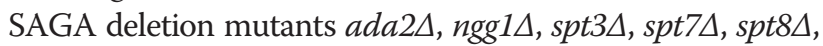
spt $20 \Delta$ and $h f i 1 \Delta$ show a severe fitness defect or lethality when combined with RPD3 deletion [43,56-59]. However deletion mutants of components of the Rpd3L complex

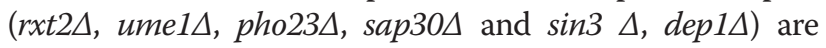
minimally or moderately sensitive to CG-1521, indicating that CG-1521 inhibits several HDACs. This correlates with the fact that none of the individual yeast HDAC deletion strains display resistance to CG-1521.

The human homologs of Gcn5, GCN5 and its paralogue PCAF (p300/CBP associated factor), the histone acetyltransferase components of the human ATAC and SAGA complexes [60], have been implicated in cancer, and these HATs are co-regulators for several protooncogenes [61]. The human homolog of Tra1, TRRAP, has been shown to bind $\mathrm{c}-\mathrm{Myc}$, leading to histone $\mathrm{H} 4$ acetylation and increased expression of Myc-dependent genes [62-64]. TRRAP interacts with the $\mathrm{N}$-terminus of c-Myc [62], and truncated Myc isoforms lacking part of the $\mathrm{N}$-terminal transactivation domain are transcriptionally 
inactive [65]. Transcriptional activation by Myc requires the GCN5 HAT activity as well as the SPT3/GCN5 interaction domain of TRRAP, suggesting that TRRAP serves as an adapter to recruit GCN5 to Myc-dependent genes $[66,67]$ and Myc has been reported to globally promote an active chromatin state, potentially by upregulating GCN5 expression [68]. GCN5/PCAF also directly acetylate Myc resulting in increased protein stability [69], which may provide a positive feedback loop through GCN5 upregulation and further Myc stabilization. Both TRRAP and GCN5 are required for Myc-dependent transformation [62,66] and upregulation of Gen 5 by Myc contributes to the block of erythroid differentiation [70]. These results suggest that, GCN5 and Myc co-operate to block differentiation and promote transformation. Given the importance of GCN5 HAT complexes for Myc-dependent transcription and transformation in human cells and the synthetic lethality of GCN5 deletion and CG-1521 treatment in yeast, it is likely that the effect of GCN5 knockdown (or inhibition of the acetyl transferase activity) combined with CG-1521 administration in Myc-driven tumors will lead to the blockade of tumor progression.

GCN5 and PCAF have been shown to regulate transcription, mediated by other transcription factors, including E2F and p53 [61,71,72]. Underlining the versatility of the human Gen5 homologs, GCN5 and PCAF have been shown to interact with BRCA2 and BRCA1, respectively. These HATs have been shown to modulate BRCA-mediated DNA repair as well as their transcriptional activation function $[73,74]$. GCN5 is also a potential target for oncogenic EGF signaling as it facilitates EGF mediated transcription through localized acetylation [75]. GCN5 and PCAF appear to be good targets for cancer therapy since they are associated with several proto-oncogenes and are not frequently mutated in human cancers [76-79].

Inhibitors for histone acetyltransferases are being developed and include garcinol and anacardic acid derivatives as well as synthetic inhibitors including isothiazolones, $\alpha$-methylene- $\gamma$-butyrolactones, and the new pyridoisothiazolone-based inhibitors that appear to be very active inhibitors of PCAF [80-83]. The $\gamma$-butyrolactone $\mathrm{MB}-3$ has been characterized as a GCN5 inhibitor in vitro and may be a potential treatment for acute lymphoblastic leukemia (ALL) [84,85]. GCN5/SAGA interacts and acetylates the oncogene E2A-PBX1 resulting in protein stabilization and in this context GCN5 inhibition results in decreased levels of the E2A-PBX1 oncogene [84]. However, as is the case with HDACis, specificity will have to be precisely determined. It will be important to determine the growth-inhibitory activity of GCN5/PCAF specific inhibitors in combination with CG-1521.

\section{Conclusion}

We have used a high throughput yeast deletion library screen to quantify strain growth after treatment with the HDACi CG-1521 and have identified 407 sensitive strains and 80 resistant strains. Biological processes including transcription and chromatin remodeling are highly represented in CG-1521-sensitive strains. In particular deletion of components of the SAGA complex, including Gcn5, confers sensitivity to CG-1521. The identification of potential pathways that modulate the response to CG-1521 in yeast will allow the evaluation of combinatorial drug targets as well as resistance markers for cancer. Based on this study we suggest that the use of HDAC inhibitors in combination with Gcn 5 inhibitors may be useful for the treatment of a variety of cancers. These combination therapies may also provide novel therapeutic approaches for Myc-driven tumors.

\section{Methods}

\section{Strains}

The S. cerevisiae library (Open Biosystems, Thermo Scientific, Hudson, NH) established by the Yeast Deletion Consortium, contains 4852 gene deletion strains on the BY4741 background (Genotype: MATa his $3 \Delta 1$ leu2 $\Delta 0$ met15 $\Delta 0$ ura3 $\Delta 0$ ) [86]. The parental strain, transformed with pYE13G (American Type Culture Collection), conferring G418 resistance, was grown in growth media containing G418, as previously described [87].

Strains DY2396, DY5925 and DY6603 were generously provided by Dr. Stillman (University of Utah Health Science Center) [88]. Strains BY4741 p416-TEF7, BY4741 gcn5 $\Delta$ p 416-TEF7 and BY4741 gcn5 4 p416-TEF7-GCN5 were generously provided by Dr. Alper (University of Texas at Austin) [89,90] (Additional file 5).

\section{Yeast deletion library screen}

The yeast deletion library screen was performed as previously described [91]. Briefly, 96 well plates were replicated in $150 \mu \mathrm{L}$ YPD, containing $200 \mu \mathrm{g} / \mathrm{mL}$ G418. The settled cell suspension was mixed and $1 \mu \mathrm{L}$ was spotted on agar plates containing a low $(55 \mu \mathrm{M})$, medium (65$70 \mu \mathrm{M})$ and a high $(70-75 \mu \mathrm{M})$ concentration of CG1521 (Errant Gene Therapeutics, Chicago, IL) using the Matrix Hydra liquid handling apparatus (Thermo Scientific, Hudson, NH). Plates were imaged after $60 \mathrm{~h}$ incubation using the AlphaImager (Alpha Innotech Corporation, San Leandro, CA). The wild-type strain and the positive control strain $(s p t 3 \Delta)$ were also spotted on each plate. The screen was performed twice (Table 5). Sensitivity and resistance was scored relative to the non-treated control and wildtype growth. Depending on the degree of sensitivity, strains were attributed a score from 1 to 3 , while resistant strains were scored on a scale of -1 to -2 . The sum of these scores across CG-1521 concentrations and biological replicates 


\section{Table 5 Study design}

\begin{tabular}{|c|c|}
\hline Experimental design & \\
\hline Plates & 57 \\
\hline Replicates & 2 \\
\hline Conditions & 0 (Control) \\
\hline \multirow[t]{3}{*}{ CG-1521 [uM] } & 55 \\
\hline & 67.5 \\
\hline & 72.5 \\
\hline Strains & 4852 \\
\hline Total number of plates & 456 \\
\hline Total number of data points & 39,729 \\
\hline
\end{tabular}

The yeast gene deletion library encompasses 57 plates (4852 strains). The complete screen was performed twice with three different concentrations of CG-1521 $(55 \mu \mathrm{M}, 67.5 \mu \mathrm{M}$ and $72.5 \mu \mathrm{M})$.

yields the final score for the respective strain. Strains with a score of $\geq 3$ were regarded as sensitive, while strains with a score of $\leq-2$ were regarded as resistant. Gene Ontology Analysis was performed using DAVID Bio-informatics Resources (Database for Annotation, Visualization and Integrated Discovery), reported $\mathrm{p}$ values have been corrected for False Discovery Rate using the methods described by Benjamini and Hochberg [28]. The screening methodology, which scores mutants as sensitive or resistant compared to the non-treated and the wild-type strain, cannot completely account for the differences in growth rates and morphologies of the deletion strain. While many of the slower growing deletion strains are not sensitive to CG-1521, the possibility that some of the sensitive strains are hypersensitive to CG-1521, due in part to their compromised growth, can not be excluded. For this reason, the sensitivity of the SAGA complex deletion strains was verified in liquid culture and agar spot assays.

\section{Validation using an agar spot assay}

Sensitivity of gene deletion strains specific to the Gcn5 HAT complex was verified as described above. Strains were spotted on agar plates containing $25 \mu \mathrm{M}, 55 \mu \mathrm{M}$ or $65 \mu \mathrm{M}$ CG-1521. Different cell concentrations were spotted using 1:20 serial dilution. Experiments using BY4741 p416-TEF7 strains were performed in synthetic dropout media lacking uracil, and sensitivity was determined using 20, 25 and $30 \mu \mathrm{M}$ CG-1521.

\section{Validation in liquid culture}

The sensitivity of strains harboring gene deletions corresponding to proteins with functions in chromatin remodeling and transcriptional regulation was verified in liquid culture. $195 \mu \mathrm{L}$ YPD containing $25 \mu \mathrm{M}, 50 \mu \mathrm{M}$ or $65 \mu \mathrm{M}$ CG-1521 were inoculated with $5 \mu \mathrm{L}$ cell suspension. After $20 \mathrm{~h}$ incubation, the cell suspension was diluted 1:2 and the $\mathrm{OD}_{600}$ was measured. To normalize for differences in growth between strains the strain growth relative to wild-type cells was calculated and the ratio of treated versus untreated control was determined and expressed as Net Treated Growth Value (NTGV). Strains with NTGVs $\leq 0.7$ are regarded as sensitive. Strains with NTGVs $\geq 1.2$ are regarded as resistant.

Exponentially growing yeast cultures (BY4741 wild-type, BY4741 gcn54, DY2396, DY5925, DY6603) were treated with 25 or $50 \mu \mathrm{M}$ CG-1521 or vehicle control (DMSO) for $20 \mathrm{~h}$, the $\mathrm{OD}_{600}$ was determined and the ratio (treated/untreated) was calculated.

\section{Cell cycle analysis}

Yeast cells, growing in log phase, were treated with $50 \mu \mathrm{M}$ CG-1521 or vehicle control (DMSO) for 1 to $4 \mathrm{~h}$. After fixation in $100 \%$ ethanol for $12-16 \mathrm{~h}$, cells were washed and $10^{7}$ cells were resuspended in $1 \mathrm{~mL} 50 \mathrm{mM}$ sodium citrate $\mathrm{pH} 7.0$ containing $100 \mu \mathrm{g} / \mathrm{mL}$ RNase A (Sigma, St. Louis, MO), incubated overnight at $55^{\circ} \mathrm{C}$ and treated with proteinase $\mathrm{K}(0.1 \mathrm{mg} / \mathrm{mL}$, Amresco, Solon, $\mathrm{OH})$ for $5 \mathrm{~h}$ at $55^{\circ} \mathrm{C}$. The cells were stained with $5 \mu \mathrm{L}$ $1 \mathrm{mg} / \mathrm{mL}$ propidium iodide for $30 \mathrm{~min}$ and the DNA content was analyzed by flow cytometry using a BD LSR2 flow cytometer (BD Biosciences, San Jose, CA). The data were analyzed using FloJo $^{\mathrm{mt}}$ software (Tree Star, Inc., Ashland, OR).

\section{Budding index analysis}

Flow cytometry results were confirmed by Budding Index Analysis. Exponentially growing yeast cultures $\left(10^{7}\right.$ cells $\left./ \mathrm{mL}\right)$ were treated with $50 \mu \mathrm{M}$ CG-1521, DMSO or $5 \mu \mathrm{g} / \mathrm{mL} \alpha$-factor (Sigma). The budding index was calculated by counting the number of unbudded and budded cells in approximately 100 yeast cells for each treatment condition.

\section{Cell death analysis}

S. cerevisiae were cultured as described above for cell cycle analysis. Aliquots were removed from the culture at 0,2 and $4 \mathrm{~h}$. The cell suspension was pelleted and resuspended in phosphate buffered saline and incubated with $1 \mu \mathrm{L}$ propidium iodide (PI) for $10 \mathrm{~min}$ in the dark. PI uptake was quantitated by flow cytometry analysis using a BD LSR2 flow cytometer (BD Biosciences). The data were analyzed using FloJo ${ }^{\text {Thx }}$ software.

\section{Statistical analysis}

For all experiments, three or more independent biological replicates were performed. The results are presented as mean $\pm \mathrm{SD}$. Results are regarded significant if $\mathrm{p}<0.05$ as established by ANOVA and Tukey-Kramer post-test. 


\section{Additional files}

Additional file 1: Sensitive and Resistant Strains. Strains are sorted according to their sensitivity or resistance to CG-1521 compared to the wild-type strain.

Additional file 2: Additional GO-Terms - Sensitive Strains. Gene ontology analysis using DAVID Bioinformatics of CG-1521 sensitive strains indicates an enrichment in ontologies, including vesicle-mediated transport and vacuolar acidification, purine nucleotide biosynthetic process, ubiquitin ligase complexes and cytoplasmic mRNA processing body in addition to chromatin remodeling and transcription. +Corrected p-values are not significant.

Additional file 3: Validation of Sensitivity. Validation of the sensitivity of CG-1521-sensitive strains in liquid culture. The net treated growth value was calculated to normalize for strain growth differences relative to the control. The data represent 3 independent experiments.

Additional file 4: Components of the Gcn5 HAT complexes and their human orthologs. The SAGA complex consists of four modules, the HAT core module (green), the DUB module (purple), the SPT module (orange) and the TAF module (blue). The SLIK complex contains an additional protein Rtg2, a truncated Spt7 and is missing Spt8. The HAT module and the ADA module (red) make up the ADA complex. GO-Analysis shows an enrichment of sensitive strains in the Gcn5 HAT complexes. Sensitive components are represented in red, insensitive deletion strains in blue. Proteins depicted in black are not present in the yeast deletion library.

Additional file 5: Yeast Strains. Yeast strains were generously provided by Dr. Stillman $\left(^{*}\right)[88]$ and Dr. Alper $\left(^{\#}\right)[89,90]$ respectively.

\section{Abbreviations}

HDAC: Histone deacetylase; HDACi: Histone deacetylase inhibitor; HAT: Histone acetyltransferase; S. cerevisiae: Saccharomyces cerevisiae; TSA: Trichostatin A; SAHA: Suberoylanilide hydroxamic acid; GO: Gene ontology; DAVID: Database for annotation, visualization and integrated discovery; SAGA complex: Spt-Ada-Gcn5-acetyltransferase complex; SLIK complex: SAGA-like complex; DUB module: Deubiquitination module; ALL: Acute lymphoblastic leukemia.

\section{Competing interests}

The authors declare that they have no competing interests.

\section{Authors' contributions}

ACG was responsible for the experimental design, data collection, analysis and interpretation, and wrote the first draft of the manuscript. TB provided expertise and oversight for the experiments, especially the screening of the yeast deletion library, assisted in the interpretation of the experimental data and edited the manuscript. MT conceived the project, assisted in the experimental design and interpretation of the experimental data and edited the manuscript. All authors read and approved the manuscript.

\section{Authors' information}

ACG is a graduate student in the Department of Biomedical Sciences, School of Public Health, University at Albany and a member of the Cancer Research Center. TB is a member of the Nanobioscience Constellation in the SUNY College of Nanoscale Science and Engineering. MT is a member of the Department of Biomedical Sciences, School of Public Health, University at Albany and Director of the Cancer Research Center

\section{Acknowledgements}

The authors would like to thank Drs. Randy Morse (Wadsworth Center, New York Department of Health) and Douglas Conklin (Cancer Research Center, University at Albany) for very useful discussions. The authors would like to thank Jan M Baumann for critically reading the manuscript, as well as Tyler Heavin for his technical assistance. The authors also thank Dr. Stillman and Dr. Alper for generously providing the DY2396, DY5925, DY6603 and BY4741 p416-TEF7 strains respectively, and Dr. Washburn for the permission to adapt the figure of the Gcn5 HAT complexes (Figure 3). ACG would like to thank the University at Albany Cancer Research Center's Fund for Memory and Hope for support.

\section{Author details}

'Department of Biomedical Sciences, School of Public Health, University at Albany, New York 12222, USA. 'Cancer Research Center, University at Albany, 1 Discovery Drive, Rensselaer, NY 12144, USA. ${ }^{3}$ Nanobioscience Constellation, SUNY-College of Nanoscale Science and Engineering, Albany, NY 12203, USA.

Received: 11 February 2014 Accepted: 18 June 2014

Published: 26 June 2014

\section{References}

1. Fraga MF, Ballestar E, Villar-Garea A, Boix-Chornet M, Espada J, Schotta G, Bonaldi T, Haydon C, Ropero S, Petrie K, lyer NG, Pérez-Rosado A, Calvo E, Lopez JA, Cano A, Calasanz MJ, Colomer D, Piris MA, Ahn N, Imhof A, Caldas C, Jenuwein T, Esteller M: Loss of acetylation at Lys 16 and trimethylation at Lys20 of histone $\mathrm{H} 4$ is a common hallmark of human cancer. Nat Genet 2005, 37:391-400.

2. Seligson DB, Horvath S, McBrian MA, Mah V, Yu H, Tze S, Wang Q, Chia D, Goodglick L, Kurdistani SK: Global levels of histone modifications predict prognosis in different cancers. Am J Pathol 2009, 174:1619-1628.

3. Seligson DB, Horvath S, Shi T, Yu H, Tze S, Grunstein M, Kurdistani SK: Global histone modification patterns predict risk of prostate cancer recurrence. Nature 2005, 435:1262-1266.

4. Wang W, Xu L, Kong J, Fan H, Yang P: Quantitative research of histone H3 acetylation levels of human hepatocellular carcinoma cells. Bioanalysis 2013, 5:327-339

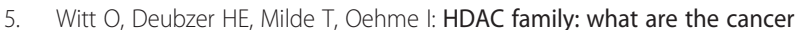
relevant targets? Cancer Lett 2009, 277:8-21.

6. Moreno DA, Scrideli CA, Cortez MAA, de Paula Queiroz R, Valera ET, da Silva Silveira V, Yunes JA, Brandalise SR, Tone LG: Differential expression of HDAC3, HDAC7 and HDAC9 is associated with prognosis and survival in childhood acute lymphoblastic leukaemia. Brit J Haematol 2010, 150:665-673.

7. Dokmanovic M, Clarke C, Marks PA: Histone deacetylase inhibitors: overview and perspectives. Mol Cancer Res 2007, 5:981-989.

8. Frew AJ, Johnstone RW, Bolden JE: Enhancing the apoptotic and therapeutic effects of HDAC inhibitors. Cancer Lett 2009, 280:125-133.

9. Dokmanovic M, Marks PA: Prospects: histone deacetylase inhibitors. J Cell Biochem 2005, 96:293-304

10. Ungerstedt JS, Sowa Y, Xu W-S, Shao Y, Dokmanovic M, Perez G, Ngo L, Holmgren A, Jiang $X$, Marks PA: Role of thioredoxin in the response of normal and transformed cells to histone deacetylase inhibitors. Proc Natl Acad Sci U S A 2005, 102:673-678.

11. Zhang C, Richon V, Ni X, Talpur R, Duvic M: Selective induction of apoptosis by histone deacetylase inhibitor SAHA in cutaneous T-cell lymphoma cells: relevance to mechanism of therapeutic action. J Invest Dermatol 2005, 125:1045-1052

12. Borbone E, Berlingieri MT, De Bellis F, Nebbioso A, Chiappetta G, Mai A, Altucci L, Fusco A: Histone deacetylase inhibitors induce thyroid cancer-specific apoptosis through proteasome-dependent inhibition of TRAIL degradation. Oncogene 2010, 29:105-116.

13. Marks PA, Breslow R: Dimethyl sulfoxide to vorinostat: development of this histone deacetylase inhibitor as an anticancer drug. Nat Biotechnol 2007, 25:84-90.

14. VanderMolen KM, McCulloch W, Pearce CJ, Oberlies NH: Romidepsin (Istodax, NSC 630176, FR901228, FK228, depsipeptide): a natural product recently approved for cutaneous T-cell lymphoma. J Antibiot 2011, 64:525-531.

15. Roy S, Packman K, Jeffrey R, Tenniswood M: Histone deacetylase inhibitors differentially stabilize acetylated p53 and induce cell cycle arrest or apoptosis in prostate cancer cells. Cell Death Differ 2005, 12:482-491.

16. Knutson AKA, Welsh J, Taylor T, Roy S, Wang W-LW, Tenniswood M: Comparative effects of histone deacetylase inhibitors on p53 target gene expression, cell cycle and apoptosis in MCF-7 breast cancer cells. Oncol Rep 2012, 27:849-853.

17. Chatterjee N, Wang W-LW, Conklin T, Chittur S, Tenniswood M: Histone deacetylase inhibitors modulate miRNA and mRNA expression, block metaphase, and induce apoptosis in inflammatory breast cancer cells. Cancer Biol Ther 2013, 14:658-671.

18. Roy S, Jeffrey R, Tenniswood M: Array-based analysis of the effects of trichostatin A and CG-1521 on cell cycle and cell death in LNCaP prostate cancer cells. Mol Cancer Ther 2008, 7:1931-1939. 
19. Roy S, Tenniswood M: Site-specific acetylation of p53 directs selective transcription complex assembly. J Biol Chem 2007, 7:4765-4771.

20. Ito T, Chiba T, Ozawa R, Yoshida M, Hattori M, Sakaki Y: A comprehensive two-hybrid analysis to explore the yeast protein interactome. Proc Natl Acad Sci U S A 2001, 98:4569-4574.

21. Ito T, Tashiro K, Muta S, Ozawa R, Chiba T, Nishizawa M, Yamamoto K, Kuhara S, Sakaki Y: Toward a protein-protein interaction map of the budding yeast: a comprehensive system to examine two-hybrid interactions in all possible combinations between the yeast proteins. Proc Natl Acad Sci U S A 2000, 97:1143-1147.

22. Tong $A H$, Evangelista $M$, Parsons $A B, X u H$, Bader $G D$, Pagé $N$, Robinson $M$, Raghibizadeh S, Hogue CW, Bussey H, Andrews B, Tyers M, Boone C: Systematic genetic analysis with ordered arrays of yeast deletion mutants. Science 2001, 294:2364-2368.

23. Hughes TR, Marton MJ, Jones AR, Roberts CJ, Stoughton R, Armour CD, Bennett HA, Coffey E, Dai H, He YD, Kidd MJ, King AM, Meyer MR, Slade D, Lum PY, Stepaniants SB, Shoemaker DD, Gachotte D, Chakraburtty K, Simon J, Bard M, Friend SH: Functional discovery via a compendium of expression profiles. Cell 2000, 102:109-126.

24. Gregoretti IV, Lee Y-M, Goodson HV: Molecular evolution of the histone deacetylase family: functional implications of phylogenetic analysis. J Mol Biol 2004, 338:17-31.

25. Langer MR, Fry CJ, Peterson CL, Denu JM: Modulating acetyl-CoA binding in the GCN5 family of histone acetyltransferases. J Biol Chem 2002, 277:27337-27344

26. Doyon Y, Côté J: The highly conserved and multifunctional NuA4 HAT complex. Curr Opin Genet Dev 2004, 14:147-154.

27. Ramachandran S, Vogel L, Strahl BD, Dokholyan NV: Thermodynamic stability of histone $\mathrm{H} 3$ is a necessary but not sufficient driving force for its evolutionary conservation. PLoS Comput Biol 2011, 7:e1001042.

28. Huang DW, Sherman BT, Lempicki RA: Systematic and integrative analysis of large gene lists using DAVID bioinformatics resources. Nat Prot 2009, 4:44-57.

29. Jantzen SG, Sutherland BJ, Minkley DR, Koop BF: GO trimming: systematically reducing redundancy in large gene ontology datasets. BMC Res Notes 2011, 4:267.

30. Lee KK, Sardiu ME, Swanson SK, Gilmore JM, Torok M, Grant P, Florens L, Workman JL, Washburn MP: Combinatorial depletion analysis to assemble the network architecture of the SAGA and ADA chromatin remodeling complexes. Mol Syst Biol 2011, 7:503.

31. Langer MR, Tanner KG, Denu JM: Mutational analysis of conserved residues in the GCN5 family of histone acetyltransferases. J Biol Chem 2001, 276:31321-31331.

32. Orpinell M, Fournier M, Riss A, Nagy Z, Krebs AR, Frontini M, Tora L: The ATAC acetyl transferase complex controls mitotic progression by targeting non-histone substrates. EMBO J 2010, 29:2381-2394.

33. Vernarecci S, Ornaghi P, Bâgu A, Cundari E, Ballario P, Filetici P: Gcn5p plays an important role in centromere kinetochore function in budding yeast. Mol Cell Biol 2008, 28:988-996.

34. Giannini G, Cabri W, Fattorusso C, Rodriquez M: Histone deacetylase inhibitors in the treatment of cancer: overview and perspectives. Future Med Chem 2012, 4:1439-1460.

35. Lane AA, Chabner BA: Histone deacetylase inhibitors in cancer therapy. J Clin Oncol 2009, 27:5459-5468.

36. Schrump DS: Cytotoxicity mediated by histone deacetylase inhibitors in cancer cells: mechanisms and potential clinical implications. Clin Cancer Res 2009, 15:3947-3957.

37. Choudhary C, Kumar C, Gnad F, Nielsen ML, Rehman M, Walther TC, Olsen JV, Mann M: Lysine acetylation targets protein complexes and co-regulates major cellular functions. Science 2009, 325:834-840,

38. Ekwall $\mathrm{K}$, Olsson T, Turner BM, Cranston G, Allshire RC: Transient inhibition of histone deacetylation alters the structural and functional imprint at fission yeast centromeres. Cell 1997, 91:1021-1032.

39. Kimata Y, Matsuyama A, Nagao K, Furuya K, Obuse C, Yoshida M, Yanagida M: Diminishing HDACs by drugs or mutations promotes normal or abnormal sister chromatid separation by affecting APC/C and adherin. J Cell Sci 2008, 121:1107-1118.

40. Cimini D, Mattiuzzo M, Torosantucci L, Degrassi F: Histone Hyperacetylation in mitosis prevents sister chromatid separation and produces chromosome segregation defects. Mol Biol Cell 2003, 14:3821-3833.
41. Shin HJ, Baek KH, Jeon AH, Kim SJ, Jang KL, Sung YC, Kim CM, Lee CW: Inhibition of histone deacetylase activity increases chromosomal instability by the aberrant regulation of mitotic checkpoint activation Oncogene 2003, 22:3853-3858.

42. Peng W, Togawa C, Zhang K, Kurdistani SK: Regulators of cellular levels of histone acetylation in Saccharomyces cerevisiae. Genetics 2008, 179:277-289.

43. Ingvarsdottir K, Krogan NJ, Emre NCT, Wyce A, Thompson NJ, Emili A, Hughes TR, Greenblatt JF, Berger SL: H2B ubiquitin protease Ubp8 and Sgf11 constitute a discrete functional module within the Saccharomyces cerevisiae SAGA complex. Mol Cell Biol 2005, 25:1162-1172.

44. Bhaumik SR: Distinct regulatory mechanisms of eukaryotic transcriptional activation by SAGA and TFIID. Biochim Biophys Acta 1809, 2011:97-108.

45. Köhler A, Schneider M, Cabal GG, Nehrbass U, Hurt E: Yeast Ataxin-7 links histone deubiquitination with gene gating and mRNA export. Nat Cell Biol 2008, 10:707-715.

46. Shukla A, Bajwa P, Bhaumik SR: SAGA-associated Sgf73p facilitates formation of the preinitiation complex assembly at the promoters either in a HAT-dependent or independent manner in vivo. Nucleic Acids Rres 2006, 34:6225-6232.

47. Jia Y, Rothermel B, Thornton J, Butow RA: A basic helix-loop-helix-leucine zipper transcription complex in yeast functions in a signaling pathway from mitochondria to the nucleus. Mol Cell Biol 1997, 17:1110-1117.

48. Liao X, Butow RRA: RTG1 and RTG2: two yeast genes required for a novel path of communication from mitochondria to the nucleus. Cell 1993, 72:61-71.

49. Rothermel BA, Shyjan AW, Etheredge JL, Butow RA: Transactivation by Rtg1p, a basic helix-loop-helix protein that functions in communication between mitochondria and the nucleus in yeast. J Biol Chem 1995, 270:29476-29482.

50. Liu Z, Sekito T, Epstein CB, Butow RA: RTG-dependent mitochondria to nucleus signaling is negatively regulated by the seven WD-repeat protein Lst8p. EMBO J 2001, 20:7209-7219.

51. Liu Z, Sekito T, Spírek M, Thornton J, Butow RA: Retrograde signaling is regulated by the dynamic interaction between Rtg2p and Mks1p. Mol Cell 2003, 12:401-411.

52. Crespo JL, Powers T, Fowler B, Hall MN: The TOR-controlled transcription activators GLN3, RTG1, and RTG3 are regulated in response to intracellular levels of glutamine. Proc Natl Acad Sci U S A 2002, 99:6784-6789.

53. Pray-Grant MG, Schieltz D, McMahon SJ, Wood JM, Kennedy EL, Cook RG, Workman JL, Yates JR, Grant PA: The novel SLIK histone acetyltransferase complex functions in the yeast retrograde response pathway. Mol Cell Biol 2002, 22:8774-8786.

54. Lee Tl, Causton HC, Holstege FC, Shen WC, Hannett N, Jennings EG, Winston F, Green MR, Young RA: Redundant roles for the TFIID and SAGA complexes in global transcription. Nature 2000, 405:701-704

55. Bu P, Evrard YA, Lozano G, Dent SYR: Loss of Gcn5 acetyltransferase activity leads to neural tube closure defects and exencephaly in mouse embryos. Mol Cell Biol 2007, 27:3405-3416.

56. Cherry JM, Hong EL, Amundsen C, Balakrishnan R, Binkley G, Chan ET, Christie KR, Costanzo MC, Dwight SS, Engel SR, Fisk DG, Hirschman JE, Hitz BC, Karra K, Krieger CJ, Miyasato SR, Nash RS, Park J, Skrzypek MS, Simison M, Weng S, Wong ED: Saccharomyces genome database: the genomics resource of budding yeast. Nucleic Acids Res 2011, 40(Database issue):D700-D705.

57. Lin YY, Qi Y, Lu JY, Pan X, Yuan DS, Zhao Y, Bader JS, Boeke JD: A comprehensive synthetic genetic interaction network governing yeast histone acetylation and deacetylation. Genes Dev 2008, 22:2062-2074.

58. Collins SR, Miller KM, Maas NL, Roguev A, Fillingham J, Chu CS, Schuldiner M, Gebbia M, Recht J, Shales M, Ding H, Xu H, Han J, Ingvarsdottir K, Cheng B, Andrews B, Boone C, Berger SL, Hieter P, Zhang Z, Brown GW, Ingles CJ, Emili A, Allis CD, Toczyski DP, Weissman JS, Greenblatt JF, Krogan NJ: Functional dissection of protein complexes involved in yeast chromosome biology using a genetic interaction map. Nature 2007, 446:806-810.

59. Costanzo M, Baryshnikova A, Bellay J, Kim Y, Spear ED, Sevier CS, Ding H, Koh JL, Toufighi K, Mostafavi S, Prinz J, St Onge RP, VanderSluis B, Makhnevych T, Vizeacoumar FJ, Alizadeh S, Bahr S, Brost RL, Chen Y, Cokol M, Deshpande R, Li Z, Lin ZY, Liang W, Marback M, Paw J, San Luis BJ, Shuteriqi $E$, Tong $A H$, van Dyk N, et al: The genetic landscape of a cell. Science 2010, 327:425-431. 
60. Spedale G, Timmers HTM, Pijnappel WWMP: ATAC-king the complexity of SAGA during evolution. Genes Dev 2012, 26:527-541.

61. Nagy Z, Tora L: Distinct GCN5/PCAF-containing complexes function as co-activators and are involved in transcription factor and global histone acetylation. Oncogene 2007, 26:5341-5357.

62. McMahon SB, Van Buskirk HA, Dugan KA, Copeland TD, Cole MD: The novel ATM-related protein TRRAP is an essential cofactor for the c-Myc and E2F oncoproteins. Cell 1998, 94:363-374.

63. Frank SR, Schroeder M, Fernandez P, Taubert S, Amati B: Binding of c-Myc to chromatin mediates mitogen-induced acetylation of histone $\mathrm{H} 4$ and gene activation. Genes \& Dev 2001, 15:2069-2082.

64. Martínez-Cerdeño V, Lemen JM, Chan V, Wey A, Lin W, Dent SR, Knoepfler PS: N-Myc and GCN5 regulate significantly overlapping transcriptional programs in neural stem cells. PLoS One 2012, 7:e39456.

65. Spotts G, Patel S, Xiao Q, Hann S: Identification of downstream-initiated c-Myc proteins which are dominant-negative inhibitors of transactivation by full-length c-Myc proteins. Mol Cell Biol 1997, 17:1459-1468.

66. McMahon S, Wood M, Cole M: The essential cofactor TRRAP recruits the histone acetyltransferase hGCN5 to c-Myc. Mol Cell Biol 2000, 20:556-562.

67. Liu X, Tesfai J, Evrard YA, Dent SYR, Martinez E: c-Myc transformation domain recruits the human STAGA complex and requires TRRAP and GCN5 acetylase activity for transcription activation. J Biol Chem 2003, 278:20405-20412.

68. Knoepfler PS, Zhang X-Y, Cheng PF, Gafken PR, McMahon SB, Eisenman RN: Myc influences global chromatin structure. EMBO J 2006, 25:2723-2734.

69. Patel J, Du Y, Ard P, Phillips C, Carella B, Chen C-J, Rakowski C, Chatterjee C, Lieberman PM, Lane WS, Blobel GA, MCMahon SB: The c-MYC oncoprotein is a substrate of the acetyltransferases hGCN5/PCAF and TIP60. Mol Cell Biol 2004, 24:10826-10834.

70. Jayapal SR, Lee KL, Ji P, Kaldis P, Lim B, Lodish HF: Down-regulation of Myc is essential for terminal erythroid maturation. $J$ Biol Chem 2010, 285:40252-40265

71. Lang SE, McMahon SB, Cole MD, Hearing P: E2F transcriptional activation requires TRRAP and GCN5 cofactors. J Biol Chem 2001, 276:32627-32634.

72. Love IM, Sekaric P, Shi D, Grossman SR, Androphy EJ: The histone acetyltransferase PCAF regulates p21 transcription through stress-induced acetylation of histone H3. Cell Cycle 2012, 11:2458-2466.

73. Fuks F, Milner J, Kouzarides T: BRCA2 associates with acetyltransferase activity when bound to P/CAF. Oncogene 1998, 17:2531-2534.

74. Oishi H, Kitagawa H, Wada O, Takezawa S, Tora L, Kouzu-Fujita M, Takada I, Yano T, Yanagisawa J, Kato S: An hGCN5/TRRAP histone acetyltransferase complex co-activates BRCA1 transactivation function through histone modification. J Biol Chem 2006, 281:20-26.

75. Cheung P, Tanner KG, Cheung WL, Sassone-Corsi P, Denu JM, Allis CD: Synergistic coupling of histone $\mathrm{H} 3$ phosphorylation and acetylation in response to epidermal growth factor stimulation. Mol Cell 2000, 5:905-915.

76. Miremadi A, Oestergaard MZ, Pharoah PDP, Caldas C: Cancer genetics of epigenetic genes. Hum Mol Genet 2007, 16 Spec No:R28-R49.

77. Ozdağ H, Batley SJ, Försti A, Iyer NG, Daigo Y, Boutell J, Arends MJ, Ponder BA, Kouzarides T, Caldas C: Mutation analysis of CBP and PCAF reveals rare inactivating mutations in cancer cell lines but not in primary tumours. Br J Cancer 2002, 87:1162-1165.

78. Shen H, Laird PW: Interplay between the cancer genome and epigenome. Cell 2013, 153:38-55.

79. You JS, Jones PA: Cancer genetics and epigenetics: two sides of the same coin? Cancer Cell 2012, 22:9-20

80. Dekker FJ, Haisma HJ: Histone acetyl transferases as emerging drug targets. Drug Discov Today 2009, 14:942-948.

81. Manzo F, Tambaro FP, Mai A, Altucci L: Histone acetyltransferase inhibitors and preclinical studies. Expert Opin Ther Pat 2009, 19:761-774.

82. Mai A, Rotili D, Tarantino D, Ornaghi P, Tosi F, Vicidomini C, Sbardella G, Nebbioso A, Miceli M, Altucci L, Filetici P: Small-molecule inhibitors of histone acetyltransferase activity: identification and biological properties. J Med Chem 2006, 49:6897-6907.

83. Furdas SD, Shekfeh S, Bissinger EM, Wagner JM, Schlimme S, Valkov V, Hendzel M, Jung M, Sippl W: Synthesis and biological testing of novel pyridoisothiazolones as histone acetyltransferase inhibitors. Bioorg Med Chem 2011, 19:3678-3689.

84. Holmlund T, Lindberg MJ, Grander D, Wallberg AE: GCN5 acetylates and regulates the stability of the oncoprotein E2A-PBX1 in acute lymphoblastic leukemia. Leukemia 2013, 27:578-585.
85. Biel M, Kretsovali A, Karatzali E, Papamatheakis J, Giannis A: Design, synthesis, and biological evaluation of a small-molecule inhibitor of the histone acetyltransferase Gcn5. Angewandte Chemie Int Ed Engl 2004, 43:3974-3976

86. Winzeler EA, Shoemaker DD, Astromoff A, Liang H, Anderson K, Andre B, Bangham R, Benito R, Boeke JD, Bussey H, Chu AM, Connelly C, Davis K, Dietrich F, Dow SW, El Bakkoury M, Foury F, Friend SH, Gentalen E, Giaever G, Hegemann JH, Jones T, Laub M, Liao H, Liebundguth N, Lockhart DJ, Lucau-Danila A, Lussier M, M'Rabet N, Menard P, et al: Functional characterization of the $\mathrm{S}$. cerevisiae genome by gene deletion and parallel analysis. Science 1999, 285:901-906.

87. Begley TJ, Rosenbach AS, Ideker T, Samson LD: Hot spots for modulating toxicity identified by genomic phenotyping and localization mapping. Mol Cell 2004, 16:117-125.

88. Yu Y, Eriksson P, Bhoite LT, Stillman DJ: Regulation of TATA-binding protein binding by the SAGA complex and the Nhp6 high-mobility group protein. Mol Cell Biol 2003, 23(6):1910-1921.

89. Alper H, Fischer C, Nevoigt E, Stephanopoulos G: Tuning genetic control through promoter engineering. Proc Natl Acad Sci U S A 2005, 102:12678-12683.

90. Lanza AM, Blazeck JJ, Crook NC, Alper HS: Linking yeast Gcn5p catalytic function and gene regulation using a quantitative, graded dominant mutant approach. PLoS One 2012, 7:e36193.

91. Begley TJ, Rosenbach AS, Ideker T, Samson LD: Damage recovery pathways in Saccharomyces cerevisiae revealed by genomic phenotyping and interactome mapping. Mol Cancer Res 2002, 1:103-112.

doi:10.1186/1471-2164-15-528

Cite this article as: Gaupel et al: High throughput screening identifies modulators of histone deacetylase inhibitors. BMC Genomics 2014 15:528.

\section{Submit your next manuscript to BioMed Central and take full advantage of:}

- Convenient online submission

- Thorough peer review

- No space constraints or color figure charges

- Immediate publication on acceptance

- Inclusion in PubMed, CAS, Scopus and Google Scholar

- Research which is freely available for redistribution 